\title{
Biotransformation of Tryptophan by Liquid Medium Culture of Psilocybe coprophila (Basidiomycetes)
}

\author{
Julio Alarcón ${ }^{\mathrm{a}, *}$, Leyla Foncea ${ }^{\mathrm{a}}$, Sergio Águila ${ }^{\mathrm{a}}$, and Joel B. Alderete ${ }^{\mathrm{b}}$ \\ a Laboratorio de Síntesis y Biotransformación de Productos Naturales, Departamento \\ Ciencias Básicas, Facultad de Ciencias, Universidad del Bío-Bío, Chillán, Chile. \\ Fax: 56-42-20 30 46. E-mail: jalarcón@pehuen.chillan.ubiobio.cl \\ b Departamento de Química Orgánica, Facultad de Ciencias Químicas, Universidad de \\ Concepción, Concepción, Chile \\ * Author for correspondence and reprint requests \\ Z. Naturforsch. 61 c, 806-808 (2006); received March 31/May 22, 2006
}

\begin{abstract}
Chemical reactions performed by fungi have been used as a modern tool in chemistry. In this work, we show the tryptophan biotransformation with Psilocybe coprophila on liquid culture medium. The results prove once more the versatility of fungi in performing a wide range of industrially attractive chemical reactions.
\end{abstract}

Key words: Biotransformation, Indole Compounds, Psilocybe coprophila

\section{Introduction}

Psilocybe fruiting bodies are small, with a typical "little brown mushroom" morphology. Macroscopically, they are characterized by their small to occasionally medium size, brown to orange-white coloration, hygrophanous pileus, and a spore print-color that ranges from medium gray-brown to dark purple-brown (though rusty-brown colored varieties are known in at least one species). Hallucinogenic species typically have a blue-staining reaction when the fruiting body is bruised. Microscopically, they are characterized by cutis-like pileipellis, lack of chrysocystidia, and smooth spores with ellipsoid, rhomboid or subhexagonal shapes, and a distinct apical germ pore. Ecologically, all species of Psilocybe are saprotrophs, growing on various kinds of decaying organic matter.

Geographically, Psilocybe species from this genus are found throughout the world in almost all biomes in a variety of habitats and substrates, with the exception of high deserts. For the bluing Psilocybe, the greatest species diversity seems to be in the neotropics, from Mesoamerica through Brazil and Chile (Guzmán, 1983). Many of the bluing species found in temperate regions, such as $P$. cyanescens, seem to have an affinity for landscaped areas mulched with woodchips and are actually rather rare in natural settings removed from human habitation. Contrary to popular belief, only a minority of Psilocybe species, such as $P$. co- prophila and $P$. cubensis, grow directly on dung. Many other species are found in habitats such as mossy, grassy, or forest humus soils. In Chile these genus is represented by $P$. argentina, $P$. semilanceata, P. zapotecorum, P. moellery and P. coprophila (Lazo, 2001).

The biotransformation of indole compounds is of special interest because of the large scope of their biological activities. They can be used to treat many diseases, such as arthritis, skin diseases, headaches and glaucoma (Gupta et al., 1996). Tryptamine, for example, has well described action on the central nervous system and can also be used as anti-feeding and anti-attractive compound over Drosophila melanogaster (O'Connor et al., 1997; Wurst et al., 1992). 5-Hydroxytryptamine is a very powerful vasoconstrictor agent called serotonin. The synthetic use of microorganisms to perform reactions in the indole nucleus has industrial interest as a way to synthesize active indole derivatives, and this research area attracts great attention. Our research team is interested in useful reactions that can be performed by microorganisms, and we have been presenting many options towards the conventional chemistry in this area (Gartz, 1989; Boaventura et al., 2004).

\section{Experimental}

\section{Organism collection}

Fruiting bodies of $P$. coprophila were collected in the Chilean VIII Region forests, growing on 
horse or cow dung. Mycelia cultures of the strain were derived from the spore print of the fruiting body. A voucher specimen of the mushroom is deposited in the herbarium of the Departamento de Ciencias Básicas de la Universidad del Bío-Bío, Chillán, Chile.

\section{Fungal strain and culture conditions}

The strains of $P$. coprophila (PCUBB-001) were cultured on potato dextrose agar (PDA), incubated for 7-10 d, and then stored at room temperature. Fermentation was carried out in Hagen medium containing the following chemicals (per liter of distilled water): $0.05 \mathrm{~g} \mathrm{CaCl} \cdot 2 \mathrm{H}_{2} \mathrm{O}$ (Merck), $0.025 \mathrm{~g} \quad \mathrm{KH}_{2} \mathrm{PO}_{4}$ (Merck), $0.25 \mathrm{~g} \quad\left(\mathrm{NH}_{4}\right)_{2} \mathrm{HPO}_{4}$ (Merck), $0.15 \mathrm{~g} \mathrm{MgSO}_{4} \cdot 7 \mathrm{H}_{2} \mathrm{O}$ (Merck), $1.3 \mathrm{ml}$ $\mathrm{FeCl}_{3} 1 \%$ (Merck ), $3.0 \mathrm{~g}$ malt extract (Merck) and $10 \mathrm{~g}$ glucose (Merck). In a $2000 \mathrm{ml}$ Erlenmeyer flask containing $500 \mathrm{ml}$ of medium with aeration and agitation $(150 \mathrm{rpm})$, the fermentation was performed. $125 \mathrm{ml}$ of well grown culture $(7 \mathrm{~d})$ in the same medium were used as inoculum. The fermentation was stopped after $30 \mathrm{~d}$. The $\mathrm{pH}$ value of the medium was adjusted to 6.5 with $\mathrm{HCl}(2 \mathrm{~m})$ or $\mathrm{KOH}(2 \mathrm{~m})$.

\section{Alkaloids isolation}

Culture filtrate $(2000 \mathrm{ml})$ obtained by filtration was acidified to $\mathrm{pH} 3$ with $0.1 \mathrm{M} \mathrm{HCl}$ and extracted with diethylether $(3 \times 200 \mathrm{ml})$. The combined extracts were dried $\left(\mathrm{Na}_{2} \mathrm{SO}_{4}\right)$ and concentrated to a final volume of $5 \mathrm{ml}$.

The mycelia were washed with $0.05 \mathrm{M} \mathrm{HCl}$ and stirred at room temperature for $1 \mathrm{~h}$, then filtered, and after acidification, extracted with diethylether $(3 \times 100 \mathrm{ml})$ for $1 \mathrm{~h}$ under stirring. The extract was dried $\left(\mathrm{Na}_{2} \mathrm{SO}_{4}\right)$ and concentrated under vacuum to a final volume of $5 \mathrm{ml}$. Then the acidic solution was alkalinized to $\mathrm{pH} 13$ with $0.1 \mathrm{~m} \mathrm{NaOH}$, stirred at room temperature for $1 \mathrm{~h}$ and extracted with diethylether. The extract was dried $\left(\mathrm{Na}_{2} \mathrm{SO}_{4}\right)$ and concentrated under vacuum to a final volume of $5 \mathrm{ml}$.

\section{Results and Discussion}

According to the literature P. coprophila is classified like a non-producing alkaloid species. In one first stage of our study, the cultures in the middle Hagen medium of this fungus did not report the presence of alkaloids. When we increased the tryptophan concentration in the culture medium and
Table I. ${ }^{1} \mathrm{H}$ NMR data $\left(\mathrm{CDCl}_{3}, 250 \mathrm{MHz}, J\right.$ in $\mathrm{Hz}$ in parentheses) for biotransformation products.

\begin{tabular}{lcl}
\hline Position & 3-Methyl-indole & Tryptamine \\
\hline H-1 & $8.65($ br s) & $9.2($ br s) \\
H-2 & $7.22(\mathrm{~m})$ & $7.72(\mathrm{~d}, 2.1)$ \\
H-4 & $8.22(\mathrm{~d}, 7.80)$ & $8.24(\mathrm{~d}, 7.81)$ \\
$\mathrm{H}-5$ & $7.82(\mathrm{t}, 7.25)$ & $7.45(\mathrm{t}, 7.29)$ \\
$\mathrm{H}-6$ & $7.15(\mathrm{t}, 7.56)$ & $7.22(\mathrm{t}, 7.42)$ \\
$\mathrm{H}-7$ & $8.05(\mathrm{~d}, 8.0)$ & $8.14(\mathrm{~d}, 8.10)$ \\
$\mathrm{H}-10$ & $2.65(\mathrm{~s})$ & $1.75(\mathrm{t}, 6.33)$ \\
$\mathrm{H}-11$ & - & $1.25(\mathrm{t}, 6.34)$ \\
$\mathrm{NH}_{2}$ & - & $0.95(\mathrm{br} \mathrm{s})$ \\
\hline
\end{tabular}

Table II. ${ }^{13} \mathrm{C}$ NMR data $\left(\mathrm{CDCl}_{3}, 65 \mathrm{MHz}\right)$ for biotransformation products.

\begin{tabular}{lcc}
\hline Position & 3-Methyl-indole & Tryptamine \\
\hline C-2 & 112.91 & 122.13 \\
C-3 & 121.81 & 113.26 \\
C-4 & 120.09 & 118.72 \\
C-5 & 128.26 & 119.03 \\
C-6 & 138.61 & 121.77 \\
C-7 & 111.54 & 111.14 \\
C-8 & 140.16 & 127.36 \\
C-9 & 141.76 & 136.40 \\
C-10 & 20.30 & 29.29 \\
C-11 & - & 42.17 \\
\hline
\end{tabular}

after cultivating by 20 days, it was possible to obtain a mixture of compounds that gave a positive Dragendorff reaction. Isolation and purification of this mixture by means of chromatography in a preparatory fine plate allowed to obtain two major compounds whose ${ }^{1} \mathrm{H}$ and ${ }^{13} \mathrm{C}$ NMR spectra (Tables I and II) correspond to 3-methyl-indole and tryptamine (Fig. 1).

Biosynthesis of tryptamine generally proceeds by enzymatic decarboxylation from the amino acid tryptophan. Tryptophan decarboxylase is the key enzyme in the early step of the terpenoid indole alkaloids biosynthetic pathway and links primary metabolism with secondary metabolism by tryptophan converting into tryptamine. Tryptamine is subsequently condensed with secologanin, resulting in strictosidine, the precursor to pharmaceutically important alkaloids such as vincristine and vinblastine (Hashimoto and Yamada, 1994).

Tryptamine molecule substitutions originate a group of compounds collectively known as tryptamines. The most well known tryptamines are serotonin, an important neurotransmitter, and melatonin, a hormone involved in regulating the sleep- 


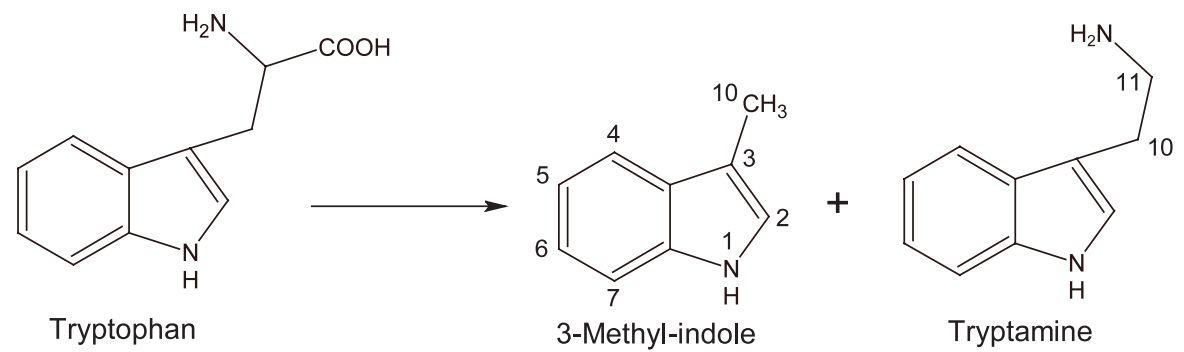

Fig. 1. Compounds obtained by tryptophan biotransformation with P. coprophila.

wake cycle. Tryptamine alkaloids found in fungi, plants and animals are commonly used by humans for their psychoactive effects, which tend to be psychedelic in nature. Prominent examples include psilocybin (from "magic mushrooms") and DMT (from numerous plant sources, e.g. Banisteriopsis caapi, also know as Ayahuasca). Many synthetic tryptamines have been made, including the migraine drug sumatriptan and its relatives.

These results show that in $P$. coprophila liquid culture, in the presence of tryptophan, synthesis

Boaventura M. A. D., Lopes R., and Takahashi J. (2004), Microorganisms as tool in modern chemistry: the biotransformation of 3-indolylacetonitrile and tryptamine by fungi. Brazilian J. Microbiol. 35, 345-347.

Gartz J. (1989), Biotransformation of tryptamine derivatives in mycelial cultures of Psilocybe. J. Basic Microbiol. 29, 347-352.

Gupta P., Lahuerta J., Jones S., Robson S. F., Samuels G. M. R., Wilson A. B., Wythes M. J., Monkhouse K. L., and Land G. C. (1996), PCT Int. Appl., WO 9611685 A2.

Guzmán G. (1983), The genus Psilocybe. Beih. Nova Hedwigia 74, 1-439. of molecules from the indole nucleus derived with bioactive projections. These findings can be useful for biosynthesis studies of interesting naturally occurring indole compounds, especially those of fungal origin.

\section{Acknowledgements}

We are grateful to Dirección de Investigación de la Universidad del Bío-Bío Grant DIUBB 033407-3R.

Hashimoto T. and Yamada Y. (1994), Alkaloid biogenesis: molecular aspects. Annu. Rev. Plant Physiol. Plant. Mol. Biol. 122, 933-944.

Lazo W. (2001), Hongos de Chile. Atlas Micológico. Facultad de Ciencias de la Universidad de Chile.

O'Connor K. E., Dobson A. D. W., and Hartmans S. (1997), Indigo formation by microorganisms expressing styrene monooxigenase activity. Appl. Environ. Microb. 63, 4287-4291.

Wurst M., Kysilka R., and Koza T. (1992), Analysis and isolation of indole alkaloids of fungi by high-performance liquid chromatography. J. Chromatogr. 583, $201-208$. 